\title{
Analisis Sistem Antrian dalam Penggunaan E-Toll untuk Menentukan Jumlah Gardu Optimal pada Gerbang Tol
}

\author{
Puji Dwi Wahyuni, Merita Bernik* \\ Fakultas Ekonomi dan Bisnis, Universitas Padjadjaran, Bandung, Indonesia \\ *merita.bernik@unpad.ac.id
}

\begin{abstract}
Considering the function of the toll road is to provide optimal services without any obstacles that can reduce the flow of vehicles, toll road providers or operators must strive for existing facilities to work optimally. Based on that, this study aims to indicate the number of optimum toll gates that should be operated to be able to control congestion and reduce the number of vehicles waiting in Pasteur 2 Toll Gate. Pasteur 2 Toll Gate is a toll gate with the heaviest volume of vehicles incorporated in the Purbaleunyi Toll Road. This toll gate is the entrance door for tourists who want to enter the city of Bandung. Vehicle volume density occurs during rush hour every day without exception at weekends, which results in the queue of vehicles. This study used a descriptive survey method by analyzing the queuing system after e-toll was implemented. Data collection is done through interviews and observations that are carried out every weekend within one month. This research was conducted to determine the optimal number of substations to be able to reduce the density that occurred. The results of this study indicate that the number of optimum substations that should be operated to be able to control congestion and reduce the number of vehicles waiting and being in the system or in smaller queues is 11 toll gates.
\end{abstract}

Keywords: E toll, M/M/s, Toll Gate, Queue System

\section{PENDAHULUAN}

Jalan tol dibangun pemerintah sebagai jalan nasional yang diwajibkan membayar jika melintasinya (Peraturan Pemerintah RI Nomor 15 Tahun 2015). Pada tahun 2018 telah dibangun $1.234 \mathrm{~km}$ jalan tol yang resmi beroperasi di Indonesia. Sepanjang $88 \mathrm{~km}$ diantaranya merupakan Jalan Tol Cipularang (Cikampek Purwakarta Padalarang) yang pembangunannya rampung pada akhir April 2005. Tujuan dibangunnya ruas jalan tol ini adalah untuk menghubungkan Jakarta-Bandung, dimana salah satu ruas jalan tol yang menghubungkan tol luar kota ke Kota
Bandung adalah Padalarang-Cileunyi (Padaleunyi). Jalan Tol Lingkar Selatan Bandung ini memiliki panjang 58,5 km dan merupakan bagian dari Jalan Tol Trans Jawa yang tergabung dalam jalan tol lanjutan dari Jalan Tol Cipularang.

Berdasarkan data yang diperoleh ternyata jumlah kendaraan yang melalui jalan tol tersebut selalu mengalami kenaikan yang bisa dilihat pada Tabel 1 di bawah ini. 
Tabel 1. Lalu Lintas Kendaraan Masuk Jalan Tol Menurut Gerbang Tol Yang Dilewati Berdasarkan Semua Jenis Golongan Tahun 2018 (Unit Kendaraan)

\begin{tabular}{lccccccc}
\hline Gerbang Tol & Jan & Feb & Mar & April & Mei & Juni & Total \\
\hline $\begin{array}{l}\text { Padalarang } \\
\text { Timur }\end{array}$ & 679.710 & 608.520 & 686.317 & 680.869 & 676.903 & 650.130 & 3.982 .449 \\
Baros 1 \& 2 & 589.495 & 558.628 & 624.440 & 610.629 & 604.202 & 536.661 & 3.524 .055 \\
Pasteur & 1.003 .833 & 933.611 & 1.036 .213 & 1.020 .031 & 996.396 & 961.179 & 5.951 .263 \\
Pasir Koja & 548.366 & 514.108 & 577.499 & 573.498 & 583.846 & 525.104 & 3.322 .421 \\
Kopo & 371.617 & 337.662 & 374.573 & 365.915 & 362.367 & 322.313 & 2.134 .447 \\
Moh. Toha & 429.510 & 394.485 & 434.643 & 429.642 & 428.010 & 336.048 & 2.452 .338 \\
Buah Batu & 619.375 & 567.029 & 637.356 & 630.318 & 619.984 & 581.334 & 3.655 .396 \\
Cileunyi & 900.013 & 825.064 & 943.928 & 924.250 & 918.660 & 987.890 & 5.499 .805 \\
Total & & & & & & & \\
\hline & 5.141 .919 & 4.739 .107 & 5.314 .969 & 5.235 .152 & 5.190 .368 & 4.900 .659 & 4.900 .659 \\
\hline
\end{tabular}

Sumber: Data Primer Diolah, 2019

Pada Tabel 1, terlihat bahwa salah satu Gerbang Tol Padaleunyi yang memiliki volume arus lalu lintas paling ramai yang biasanya dilewati kendaraan adalah Gerbang Tol Pasteur dimana menempati urutan pertama dan kemudian disusul oleh Gerbang Tol Cileunyi. Gerbang Tol Pasteur sendiri terbagi menjadi 2 bagian yakni Gerbang Tol Pasteur 1 yang merupakan Gerbang Masuk Tol menuju Jakarta ataupun Cileunyi dari Kota Bandung dan Gerbang Tol Pasteur 2 yang merupakan gerbang keluar tol untuk masuk ke Kota Bandung. Gerbang Tol Pasteur 2 memiliki delapan gardu tol dengan pengoperasian hariannya dibagi menjadi tiga shift kerja. Jumlah volume kendaraan pada shift 1 dan 2 pada tahun 2018 sebesar 1.942.890 dan 1.870.106 sedangkan pada shift 3 hanya 607.404. Hal tersebut menunjukkan bahwa dengan pengoperasian delapan gardu tol pada masing-masing shift dinilai sangatlah tidak efektif jika melihat dari jumlah volume kendaraan yang melintas di masing-masing shif. Ketidakseimbangan antrian dengan mengandalkan 3 shift kerja juga terjadi pada gerbang Tol Cililitan yang memiliki 18 gardu pembayaran (Santoso et $a l, 2015)$. Selain itu dengan dipergunakan $e$ toll menyebabkan antrian yang cukup panjang untuk shift 1 dan 2. Penentuan jumlah gardu untuk masing-masing shift belum dapat mengurai kepadatan dan antrian kendaraan yang terjadi, maka perlu ditentukan jumlah gardu yang paling optimal untuk masing-masing shift 1 dan 2 . Oleh karena itu, penelitian ini bertujuan untuk mengetahui jumlah gardu yang paling optimal untuk masing-masing shift tersebut.

Russel dan Taylor (2011)

berpendapat bahwa antrian terjadi karena adanya sekumpulan orang atau barang yang tiba lebih awal pada server dari waktu mereka dapat dilayani. Model antrian berdasarkan Heizer dan Render (2017) terdapat empat jenis yaitu model A (M/M/I) single service queing model with Poisson arrivals and Exponential service times, model B (M/M/S) Multhichannel system queing model, model $\mathrm{C}(\mathrm{M} / \mathrm{D} / \mathrm{I})$ constant service time model dan model $\mathrm{D}$ limited population (finite population) model.

Penelitian yang dilakukan oleh Vass dan Szabo (2015) menyatakan bahwa analisis data dan model antrian yang digunakan untuk memperbaiki antrian pada Emergency Depertement (IGD) dengan menggunakan model $\mathrm{M} / \mathrm{M} / 3$ dapat membantu pengambilan keputusan untuk menentukan solusi yang optimum. Teori antrian ini juga dipergunakan untuk memperbaiki antrian nasabah pada bank dengan sistem antrian multi server dimana variabel dalam penelitian ini adalah kinerja antrian. Hasilnya dengan menambah lima teller yang beroperasi ternyata mengurangi antrian, sebesar 58,4\% (Berhan, 2015).

\section{METODE}

Metode penelitian yang digunakan adalah metode penelitian deskriptif survei. Penelitian ini dilakukan dengan melihat dan mengobservasi langsung sistem antrian pada kendaraan yang melintas di Gerbang Tol Pasteur 2. Observasi dilakukan pada sistem antrian yang terjadi pada gardu tol yang terdapat di Gerbang Tol Pasteur 2. Observasi ini bertujuan untuk mendapatkan gambaran mengenai kinerja antrian kendaraan pada Gardu Tol di Gerbang Tol Pasteur 2. Hasil observasi tersebut kemudian dianalisis dan ditarik kesimpulan sehingga dapat diberikan saran untuk meningkatkan efisiensi dan efektifitas operasional, khususnya pada sistem antrian kendaraan yang melintas di Gerbang Tol Pasteur 2 dengan cara mengoptimalkan keberadaan gardu tol yang tersedia. 
Analisis yang dilakukan adalah sebagai berikut:

1. Menentukan jumlah gerbang tol yang beropersi melalui wawancara dengan petugas jalan tol yang berwenang

2. Jumlah kedatangan kendaraan yang diperoleh dari data sekunder mengenai jumlah kendaraan yang melewati gerbang Tol Pasteur

3. Waktu antar kedatangan kendaraan, data ini diperoleh melalui observasi. Setelah didapatkan data waktu antar kedatagan dilakukan perhitungan rata-rata waktu antar kedatangan dengan rumus (Heizer et al, 2017):

$$
\lambda=\frac{\sum n}{t}
$$

4. Waktu pelayanan masing-masing gardu, data ini diperoleh dengan observasi langsung, dimana rumus perhitungannya:

$$
\mu=\frac{\lambda}{N}
$$

5. Rata-rata jumlah konsumen atau unit dalam sistem, $L_{s}$, dengan rumus:

$$
L_{s}=\frac{\lambda \mu(\lambda / \mu)^{M}}{(M-1) !\left(M_{\mu}-\lambda\right)^{2}} P_{0}+\frac{\lambda}{\mu}
$$

6. Rata-rata waktu yang dihabiskan satu konsumen atau unit dalam suatu system, $\mathrm{W}_{\mathrm{s}}$, dengan rumus seperti di bawah ini :

$$
W_{s}=\frac{L s}{\lambda}
$$

7. Rata-rata jumlah konsumen atau unit yang menunggu dalam antrian, $\mathrm{L}_{\mathrm{q}}$. dengan rumus seperti di bawah ini :

$$
L_{q}=L s-\frac{\lambda}{\mu}
$$

8. Rata-rata waktu yang dihabiskan satu konsumen unit menunggu dalam antrian, $\mathrm{W}_{\mathrm{q}}$, dengan rumus seperti di bawah ini:

$$
W_{q}=\frac{L q}{\lambda}
$$

9. Probabilitas terdapat 0 orang dalam sistem, $\mathrm{P}_{0}$, dengan rumus seperti di bawah ini:

$$
P_{0}=\frac{1}{\left[\sum_{n=0}^{M-1} \frac{1}{n !}\left(\frac{\lambda}{\mu}\right)^{n}\right]+\frac{1}{m !}\left(\frac{\lambda}{\mu}\right)^{m} \frac{m \mu}{m \mu-\lambda}} \text { for } m \mu>\lambda
$$

10. Faktor utilitas, dengan rumus seperti di bawah ini:

$$
\rho=\frac{\lambda}{\text { jumlah gardu } \cdot \mu}
$$

Berdasarkan langkah-langkah di atas, maka pengolahan data pada penelitian ini dilakukan dengan menggunakan POM QM.

\section{HASIL DAN PEMBAHASAN}

Gerbang Tol Pasteur 2 merupakan gerbang tol yang menggunakan sistem tertutup, yaitu pengguna jalan mengambil tiket di gerbang tol masuk dan membayar di gerbang keluar. Gerbang Tol Pasteur 2 menggunakan model antrian $\mathrm{M} / \mathrm{M} / \mathrm{s}$ dengan kedatangan berdistribusi poisson dengan waktu pelayanan distribusi eksponensial negatif, dan pelayanan dilakukan secara first come, first served. Gerbang Tol Pasteur 2 memiliki 8 gardu tol dengan pengoperasian hariannya dibagi menjadi 3 shift kerja.

Berdasarkan Peraturan Menteri Pekerjaan Umum dan Perumahan Rakyat Nomor 16/PRT/M/2017 Tahun 2017 tentang Transaksi Tol Nontunai di Jalan Tol dimana penerapan transaksi tol nontunai sepenuhnya berlaku di seluruh jalan tol per 31 Oktober 2017. Penerapan transaksi tol nontunai ini merupakan sistem pembayaran dengan menggunakan uang elektronik sebagai salah satu bentuk teknologi dalam transaksi pembayaran tol nontunai di jalan tol. Diterapkannya kebijakan transaksi nontunai mengakibatkan terjadi perampingan petugas toll collector, yang semula saat diberlakukannya sistem pembayaran tunai masing-masing gardu diisi oleh satu petugas toll collector, setelah diberlakukannya transaksi non tunai satu petugas toll collector bertanggung jawab atas operasional tiga gardu pembayaran GTO (Gardu Tol Otomatis) atau saldo cukup terkecuali gardu pembayaran saldo kurang/top-up masingmasing gardu diharuskan diisi oleh satu petugas toll collector. Saat ini gerbang tol pasteur 2, memiliki 6 GTO dan 2 gardu saldo kurang. Hal ini berarti terdapat empat petugas toll collector yang bertugas setiap shift-nya. 
Tingkat Kedatangan Kendaraan di Gerbang Exit Tol Pasteur 2 dengan Sistem Pembayaran Nontunai/E-Toll pada Shift I

Tingkat kedatangan kendaraan dihitung dengan menggunakan formula :

$\lambda=\frac{\sum n}{t}=\frac{126.699}{64}=$

$1.979,6719$ kendaraan/jam

Dimana:

$\lambda=$ tingkat kedatangan kendaraan

$\mathrm{t}=$ total waktu operasional

$\mathrm{n}=$ panjang kedatangan kendaraan

Berdasarkan hasil perhitungan di atas didapatkan hasil tingkat kedatangan kendaraan pada shift I sebesar 1979,6719.

Tingkat Pelayanan Kendaraan di Gerbang Exit Tol Pasteur 2 dengan Sistem Pembayaran Nontunai (E-Toll) pada Shift I

Jumlah rata-rata pelayanan kendaraan dinotasikan dengan symbol $\mu$. Pada kasus ini jumlah rata-rata pelayanan diasumsikan sama untuk setiap kondisi kerjanya. Hal ini disebabkan pelayanan untuk setiap konsumen dilakukan dengan kemampuan yang sama. Pengambilan data dilakukan pada kondisi weekend shift 1 , yang masing-masing pengamatan dilakukan setiap 5 menit, sehingga didapatkan data sebanyak 120. Maka didapatkan waktu rata-rata pelayanan sebagai berikut

$$
\begin{array}{r}
\frac{1}{\mu}=\bar{X}=\frac{\sum X_{i}}{n}=\frac{1080}{120}=9 \text { detik } \\
\mu=\frac{1 \times 3600}{9}=400 \text { kendaraan } / \text { jam }
\end{array}
$$

\section{Analisis Kebutuhan Jumlah Gardu Minimum Shift I}

Penentuan kebutuhan jumlah gardu minimum dapat diketahui dengan menentukan tingkat utilitas fasilitas pelayanan sehingga dapat mengetahui kesibukan atau utilitas kerja setiap server yang dibuka. Pada kasus ini utilitas fasilitas pelayanan berfungsi untuk mengetahui kebutuhan gardu minimum yang dibuka, karena apabila gardu yang dibuka terlalu sedikit maka antrian yang akan terjadi tidak akan terkendali. Perhitungan utilitas pada gerbang tol Pasteur Bandung yaitu pada shift 1 dan shif 2 tahun 2014 menunjukan hasil yang belum maksimal,sehingga berdampak pada peningkatan antrian (Anthara, 2014). Tingkat utilitas fasilitas pelayanan dapat diketahui dengan cara :

$$
\rho=\frac{\lambda}{s . \mu}<1
$$

Rumus diatas menunjukkan apabila nilai $\rho$ lebih besar dari 1 maka akan terjadi antrian yang tidak terkendali, dan jika $\rho$ yang dihasilkan lebih kecil dari 1 maka antrian kendaraan yang terjadi dapat terkendali. Perhitungan tingkat utilitas fasilitas pelayanan dilakukan hingga sebelas gardu. Hal ini dilakukan untuk melihat utilitas gardu jika dilakukan penambahan. Tingkat utilitas fasilitas pelayanan untuk setiap kondisi kerjan pada shift I adalah sebagai berikut :

1. Jika gardu yang dibuka $1(\mathrm{~s}=1)$, maka: $\rho=\frac{1979,67}{(1) 400}=4,949$ (karena > 1, maka antrian tidak terkendali)

2. Jika gardu yang dibuka $2(\mathrm{~s}=2)$, maka: $\rho=\frac{1979,67}{(2) 400}=2,475$ (karena > 1 , maka antrian tidak terkendali)

3. Jika gardu yang dibuka $3(\mathrm{~s}=3)$, maka: $\rho=\frac{1979,67}{(3) 400}=1,649$ (karena > 1, maka antrian tidak terkendali)

4. Jika gardu yang dibuka $4(\mathrm{~s}=4)$, maka $\rho=\frac{1979,67}{(4) 400}=1,237$ (karena > 1, maka antrian tidak terkendali)

5. Jika gardu yang dibuka $5(\mathrm{~s}=5)$, maka $\rho=\frac{1979,67}{(5) 400}=0,989$ (karena $<1$, maka antrian terkendali)

Hasil perhitungan tingkat utilitas pelayanan $(\rho)$ pada kondisi weekend shift I dihasilkan jumlah gardu minimum yang dibutuhkan sebesar 5, jika jumlah gardu yan dibuka lebih kecil dari 5 maka antrian yang terjadi tidak terkendali. 
Analisis Kinerja Sistem Antrian di Gerbang Exit Tol Pasteur 2 dengan Sistem Pembayaran Nontunai pada Shift I

Setelah diketahui tingkat kedatangan dan tingkat pelayanan kendaraan, maka selanjutnya menghitung kinerja antrian. Analisis kinerja antrian diukur oleh variabel antrian yang bertujuan untuk mengetahui waktu dan banyak pelanggan dalam antrian maupun sistem. Perhitungan variabel antrian dimulai dari kebutuhan gardu minimum yang dibutuhkan berdasarkan hasil perhitungan tingkat utilitas fasilitas pelayanan yang telah dilakukan sebelumnya. Perhitungan variabel antrian ini dilakukan hingga kebutuhan gardu mencapai $11(\mathrm{~s}=11)$.

Berikut ini merupakan tabel rekapitulasi perhitungan variabel antrian untuk shift I:

Tabel 2. Rekapitulasi Perhitungan Variabel Antrian Pada Saat Shift I

\begin{tabular}{ccccccc}
\hline S & $\begin{array}{c}\mathrm{P} \\
(\%)\end{array}$ & $\begin{array}{c}\text { Lq } \\
\text { (Kendar } \\
\text { aan) }\end{array}$ & $\begin{array}{c}\text { Ls } \\
\text { (Kend } \\
\text { araan) }\end{array}$ & $\begin{array}{c}\text { Wq } \\
(\text { Menit } \\
\text { ) }\end{array}$ & $\begin{array}{c}\text { Ws } \\
(\mathrm{Me} \\
\text { nit) }\end{array}$ & $\begin{array}{c}\mathrm{P} 0( \\
\%)\end{array}$ \\
\hline 5 & 0,98 & 94,9142 & 99,863 & 2,876 & 3,02 & 0,00 \\
& 9836 & 45965 & 43 & 66598 & 664 & 04 \\
6 & 0,82 & 2,68164 & 7,6308 & 0,081 & 0,23 & 0,00 \\
& 4863 & 1889 & 22 & 27534 & 13 & 4885 \\
7 & 0,70 & 0,75324 & 5,7024 & 0,022 & 0,17 & 0,00 \\
& 7026 & 1906 & 22 & 82928 & 28 & 6337 \\
8 & 0,61 & 0,25941 & 5,2085 & 0,007 & 0,15 & 0,00 \\
& 8647 & 8151 & 98 & 86246 & 786 & 6831 \\
9 & 0,54 & 0,09331 & 5,0424 & 0,002 & 0,15 & 0,00 \\
& 9909 & 0167 & 9 & 82804 & 282 & 7002 \\
10 & 0,49 & 0,03328 & 4,9824 & 0,001 & 0,15 & 0,00 \\
& 4918 & 1899 & 62 & 00872 & 102 & 706 \\
11 & 0,44 & 0,01150 & 4,9606 & 0,000 & 0,15 & 0,00 \\
& 9925 & 9193 & 89 & 34884 & 036 & 708 \\
\hline
\end{tabular}

Sumber : Data Primer Diolah, 2019

Tingkat Kedatangan Kendaraan di Gerbang Exit Tol Pasteur 2 dengan Sistem Pembayaran Nontunai (E-Toll) pada Shift II

Tingkat kedatangan kendaraan dihitung dengan menggunakan formula

$$
\begin{aligned}
& \lambda=\frac{\sum n}{t}=\frac{117855}{64}= \\
& 1.841,484 \text { kendaraan/jam }
\end{aligned}
$$

Dimana:

$\lambda=$ tingkat kedatangan kendaraan

$\mathrm{t}=$ total waktu operasional

$\mathrm{n}=$ panjang kedatangan kendaraan

Berdasarkan hasil perhitungan diatas

didapatkan hasil tingkat kedatangan kendaraan pada shift II sebesar 1841,484.
Tingkat Pelayanan Kendaraan di Gerbang Exit Tol Pasteur 2 dengan Sistem Pembayaran Nontunai (E-Toll) pada Shift II

Jumlah rata-rata pelayanan kendaraan dinotasikan dengan symbol $\mu$. Pada kasus ini jumlah rata-rata pelayanan diasumsikan sama untuk setiap kondisi kerjanya, hal ini dikarenakan pelayanan untuk setiap konsumen dilakukan dengan kemampuan yang sama. Pengambilan data dilakukan pada kondisi weekend shift II, yang masing-masing pengamatan dilakukan setiap lima menit, sehingga didapatkan data sebesar 120, maka didapatkan waktu ratarata pelayanan sebagai berikut :

$\frac{1}{\mu}=\bar{X}=\frac{\sum X_{i}}{n}=\frac{1115}{120}=9,29 \mathrm{detik}$

$\mu=\frac{1 \times 3600}{9,29}=389,51$ kendaraan $/ \mathrm{jam}$

\section{Analisis Kebutuhan Jumlah Gardu Minimum Shift II}

Tingkat utilitas fasilitas pelayanan untuk setiap kondisi kerjan pada shift II adalah sebagai berikut :

1. Jika gardu yang dibuka $1(\mathrm{~s}=1)$, maka: $\rho=\frac{1841.484}{(1) 389,51}=4.727$ (karena $>1$, maka antrian tidak terkendali)

2. Jika gardu yang dibuka $2(\mathrm{~s}=2)$, maka: $\rho=\frac{1841.484}{(2) 389,51}=2.364$ (karena $>1$, maka antrian tidak terkendali)

3. Jika gardu yang dibuka $3(\mathrm{~s}=3)$, maka: $\rho=\frac{1841.484}{(3) 389,51}=1.576$ (karena $>1$, maka antrian tidak terkendali)

4. Jika gardu yang dibuka $4(\mathrm{~s}=4)$, maka: $\rho=\frac{1841.484}{(4) 389,51}=1.181$ (karena $>1$, maka antrian tidak terkendali)

5. Jika gardu yang dibuka $5(\mathrm{~s}=5)$, maka: $\rho=\frac{1841.484}{(5) 389,51}=0.945($ karena $<1$, maka antrian terkendali)

Hasil perhitungan tingkat utilitas pelayanan $(\rho)$ pada kondisi weekend shift II dihasilkan jumlah gardu minimum yang dibutuhkan sebesar 5, jika jumlah gardu yan dibuka lebih kecil dari 5 maka antrian yang 
terjadi tidak terkendali. Pradana et al. (2018) menyatakan apabila utilitas kurang daripada satu maka tidak akan terjadi antrian yang panjang. Hal tersebut terjadi pada gerbang tol Pelabuhan Bakauheni yang apabila tersedia lebih dari lima gerbang tol, tidak akan terjadi antrian yang sangat panjang.

\section{Analisis Kinerja Sistem Antrian di Gerbang Exit Tol Pasteur 2 dengan Sistem Pembayaran Nontunai pada Shift II}

Setelah diketahui tingkat kedatangan dan tingkat pelayanan kendaraan, maka selanjutnya menghitung kinerja antrian. Analisis kinerja antrian diukur oleh variabel antrian yang bertujuan untuk mengetahui waktu dan banyak pelanggan dalam antrian maupun sistem. Perhitungan variabel antrian dimulai dari kebutuhan gardu minimum yang dibutuhkan berdasarkan hasil perhitungan tingkat utilitas fasilitas pelayanan yang telah dilakukan sebelumnya. Perhitungan variabel antrian ini dilakukan hingga kebutuhan gardu mencapai $11(s=11)$. Berikut ini merupakan tabel rekapitulasi perhitungan variabel antrian untuk shift II:

Tabel 3. Rekapitulasi Perhitungan Variabel Antrian pada Shift II

\begin{tabular}{lllllll}
\hline S & $P(\%)$ & Lq (Kendaraan) & $\begin{array}{c}\text { Ls } \\
\text { (Kendaraan) }\end{array}$ & Wq (Menit) & $\begin{array}{c}\text { Ws } \\
\text { (Menit) }\end{array}$ & Po(\%) \\
\hline 5 & 0,989836 & 94,914245965 & 99,86343 & 2,87666598 & 3,02664 & 0,0004 \\
6 & 0,824863 & 2,681641889 & 7,630822 & 0,08127534 & 0,2313 & 0,004885 \\
7 & 0,707026 & 0,753241906 & 5,702422 & 0,02282928 & 0,1728 & 0,006337 \\
8 & 0,618647 & 0,259418151 & 5,208598 & 0,00786246 & 0,15786 & 0,006831 \\
9 & 0,549909 & 0,093310167 & 5,04249 & 0,00282804 & 0,15282 & 0,007002 \\
10 & 0,494918 & 0,033281899 & 4,982462 & 0,00100872 & 0,15102 & 0,00706 \\
11 & 0,449925 & 0,011509193 & 4,960689 & 0,00034884 & 0,15036 & 0,00708 \\
\hline \multicolumn{5}{l}{ Sumber : Data Primer Diolah, 2019}
\end{tabular}

\section{Pemilihan Solusi yang Paling Optimal untuk Masing-Masing Shift pada Kondisi Antrian Saat Ini}

Pencarian alternatif solusi untuk dapat mengendalikan antrian yang terjadi di Gerbang Tol Pasteur 2 dilakukan dengan menghitung kinerja sistem antrian dengan jumlah fasilitas 5-11 fasilitas pelayanan (server) untuk shift I.
Tabel 4. Kinerja Sistem Antrian dengan Jumlah 5 -11 Fasilitas Pelayanan (Server)

\begin{tabular}{ccccccc}
\hline $\mathrm{S}$ & $\mathrm{P}(\%)$ & $\begin{array}{c}\mathrm{Lq} \\
(\text { Kendaraa } \\
\mathrm{n})\end{array}$ & $\begin{array}{c}\mathrm{Ls} \\
(\text { Kendara } \\
\text { an) }\end{array}$ & $\begin{array}{c}\text { Wq } \\
(\text { Menit) }\end{array}$ & $\begin{array}{c}\text { Ws } \\
(\text { Meni } \\
\mathrm{t})\end{array}$ & $\mathrm{P} 0(\%)$ \\
\hline 5 & 0,9898 & 94,914245 & 99,8634 & 2,87666 & 3,026 & 0,0004 \\
& 36 & 965 & 3 & 598 & 64 & \\
6 & 0,8248 & 2,6816418 & 7,63082 & 0,08127 & 0,231 & 0,0048 \\
& 63 & 89 & 2 & 534 & 3 & 85 \\
7 & 0,7070 & 0,7532419 & 5,70242 & 0,02282 & 0,172 & 0,0063 \\
& 26 & 06 & 2 & 928 & 8 & 37 \\
8 & 0,6186 & 0,2594181 & 5,20859 & 0,00786 & 0,157 & 0,0068 \\
& 47 & 51 & 8 & 246 & 86 & 31 \\
9 & 0,5499 & 0,0933101 & 5,04249 & 0,00282 & 0,152 & 0,0070 \\
& 09 & 67 & & 804 & 82 & 02 \\
10 & 0,4949 & 0,0332818 & 4,98246 & 0,00100 & 0,151 & 0,0070 \\
& 18 & 99 & 2 & 872 & 02 & 6 \\
11 & 0,4499 & 0,0115091 & 4,96068 & 0,00034 & 0,150 & 0,0070 \\
& 25 & 93 & 9 & 884 & 36 & 8 \\
\hline
\end{tabular}

Sumber : Data Primer Diolah, 2019

Berdasarkan hasil perhitungan kinerja antrian pada Tabel 4.9, dapat dibandingkan tingkat kesibukan antara ketujuh alternatif tersebut maka dengan membuka delapan fasilitas pelayanan (server) seperti yang sudah diberlakukan saat ini merupakan solusi terbaik yang sudah dilakukan. Dengan tingkat kesibukan $61,86 \%$ pelayanan masih dapat berjalan baik di mana terdapat kemungkinan 38,14\% fasilitas pelayanan sedang tidak memberikan pelayanan. Sedangkan jika dibandingkan berdasarkan jumlah kendaraan dalam sistem maupun dalam antrian dan waktu yang dihabiskan oleh masing-masing kendaraan dalam sistem maupun dalam antrian, maka alternatif terbaik dengan membuka sebelas gardu. Dengan membuka sebelas gardu kemungkinan kendaraan menunggu dan berada dalam sistem ataupun dalam antrian menjadi lebih kecil. Adapun hasil perbandingannya dapat dilihat pada Tabel 5 berikut ini:

Tabel 5. Perbandingan Operasional 8 Gardu dan 11 Gardu

\begin{tabular}{ccccccc}
\hline $\mathrm{S}$ & $\begin{array}{c}\mathrm{P} \\
(\%)\end{array}$ & $\begin{array}{c}\text { Lq } \\
\text { Kenda } \\
\text { raan) }\end{array}$ & $\begin{array}{c}\text { Ls } \\
(\text { Kenda } \\
\text { raan) }\end{array}$ & $\begin{array}{c}\text { Wq } \\
\text { (Menit) }\end{array}$ & $\begin{array}{c}\text { Ws } \\
(\text { Men } \\
\text { it) }\end{array}$ & $\begin{array}{c}\text { P0( } \\
\%)\end{array}$ \\
\hline $\mathbf{8}$ & 0,61 & 0,2594 & 5,2085 & 0,0001 & 0,00 & 0,00 \\
$\mathbf{1}$ & 8647 & 18151 & 98 & 31041 & 2631 & 6831 \\
$\mathbf{1}$ & 9,44 & 0,0115 & 4,9606 & 0,0000 & 0,00 & 0,00 \\
\end{tabular}

Sumber : Data Primer Diolah, 2019

Tabel 5 menunjukkan perbandingan hasil kinerja antrian dengan operasional 8 gardu dan 11 gardu yang mengalami penurunan secara signifikan terhadap tingkat 
utilitas sebesar $16,87 \%$. Penurunan kinerja antrian pun terjadi pada rata-rata waktu menunggu dalam antrian sebesar 0,000125227 menit. Perbedaan operasinal gardu dari 8 menjadi 11 tidak memberikan pengaruh yang signifikan terhadap rata-rata jumlah kendaraan yang menunggu dalam sistem maupun antrian, rata-rata waktu menunggu dalam sistem dan probabilitas tidak ada kendaraan dalam sistem.

Selanjutnya pencarian alternatif solusi untuk dapat mengendalikan antrian yang terjadi di Gerbang Tol Pasteur 2 dilakukan dengan menghitung kinerja sistem antrian dengan jumlah fasilitas 5-11 fasilitas pelayanan (server) untuk shift II. Penambahan fasilitas pelayanan untuk meningkatkan kinerja antrian juga sejalan dengan penelitian yang dilakukan oleh $\mathrm{Na}$ dan Zhiqin (2015), Sya'diyah dan Suryowati (2017) dan Prayogi, Pondang dan Tumewu (2017).

Tabel 6. Kinerja Sistem Antrian Dengan Jumlah 5 Hingga 11 Fasilitas Pelayanan (Server)

\begin{tabular}{cccccccc}
\hline \multirow{2}{*}{$\mathrm{S}$} & $\mathrm{P}(\%)$ & $\begin{array}{c}\text { Lq } \\
\text { (Kendaraan) }\end{array}$ & $\begin{array}{c}\text { Ls } \\
\text { Kendaraan) }\end{array}$ & Wq (Menit) & $\begin{array}{c}\text { Ws } \\
(\text { Meni }\end{array}$ & P0(\%) \\
\hline $\mathbf{5}$ & 0,945539 & 15,056483325 & 19,78418 & 0,49057662 & 0,64464 & 0,0024 \\
6 & 0,787949 & 1,834378133 & 6,562072 & 0,05976846 & 0,21378 & 0,00675 \\
7 & 0,675385 & 0,546736739 & 5,274431 & 0,017814 & 0,17184 & 0,008144 \\
8 & 0,590962 & 0,188266449 & 4,91596 & 0,00613416 & 0,1602 & 0,008611 \\
9 & 0,525299 & 0,066468361 & 4,794162 & 0,0021654 & 0,15618 & 0,008769 \\
10 & 0,472769 & 0,023064932 & 4,750759 & 0,0007518 & 0,1548 & 0,008822 \\
11 & 0,42979 & 0,007719534 & 4,735413 & 0,0002514 & 0,15432 & 0,008839 \\
\multicolumn{5}{l}{ Sumber : Data Primer Diolah, 2019 }
\end{tabular}

Berdasarkan hasil perhitungan kinerja antrian pada Tabel 6 dapat dibandingkan tingkat kesibukan antara ketujuh alternatif tersebut maka dengan membuka delapan fasilitas pelayanan (server) seperti yang sudah diberlakukan saat ini merupakan solusi terbaik yang sudah dilakukan. Dengan tingkat kesibukan $59,09 \%$ pelayanan masih dapat berjalan baik di mana terdapat kemungkinan 40,91\% fasilitas pelayanan sedang tidak memberikan pelayanan. Sedangkan jika dibandingkan berdasarkan jumlah kendaraan dalam sistem maupun dalam antrian dan waktu yang dihabiskan oleh masing-masing kendaraan dalam sistem maupun dalam antrian, maka alternatif terbaik dengan membuka sebelas gardu. Diharapkan dengan membuka sebelas gardu kemungkinan kendaraan menunggu dan berada dalam sistem ataupun dalam antrian menjadi lebih kecil. Adapun hasil perbandingannya dapat dilihat pada Tabel 7 berikut ini

Tabel 7. Perbandingan Operasional 8 Gardu dan 11 Gardu

\begin{tabular}{ccccccc}
\hline S & $\begin{array}{c}\mathrm{P} \\
(\%)\end{array}$ & $\begin{array}{c}\text { Lq } \\
\text { Kenda } \\
\text { raan) }\end{array}$ & $\begin{array}{c}\text { Ls } \\
\text { (Kenda } \\
\text { raan) }\end{array}$ & $\begin{array}{c}\text { Wq } \\
(\text { Menit })\end{array}$ & $\begin{array}{c}\text { Ws } \\
(\text { Men } \\
\text { it })\end{array}$ & $\begin{array}{c}\text { P0( } \\
\%)\end{array}$ \\
\hline 8 & 0,59 & 0,1882 & 4,9159 & 0,0001 & 0,00 & 0,00 \\
1 & 0962 & 66449 & 6 & 02236 & 267 & 8611 \\
1 & 0,42 & 0,0077 & 4,7354 & 0,0000 & 0,00 & 0,00 \\
\multicolumn{7}{l}{ Sumber : Data Primer Diolah, 2019 }
\end{tabular}

Tabel 7 menunjukkan perbandingan hasil kinerja antrian dengan operasional 8 gardu dan 11 gardu yang mengalami penurunan secara signifikan terhadap tingkat utilitas sebesar $16,11 \%$. Penurunan kinerja antrian pun terjadi pada rata-rata waktu menunggu dalam sistem sebesar 0,000098 menit dan rata-rata waktu menunggu dalam antrian sebesar 0,000098 menit. Perbedaan operasinal gardu dari 8 menjadi 11 tidak memberikan pengaruh yang signifikan terhadap rata-rata jumlah kendaraan yang menunggu dalam sistem maupun antrian dan probabilitas tidak ada kendaraan dalam sistem.

\section{Kesimpulan}

Berdasarkan analisis yang telah dilakukan, dapat disimpulkan bahwa, gerbang Tol Pasteur 2 menggunakan model antrian $\mathrm{M} / \mathrm{M} / \mathrm{s}$ dengan kedatangan berdistribusi poisson dengan waktu pelayanan distrbusi eksponensial negatif, dan pelayanan dilakukan secara first come, first served. Perubahan sistem pembayaran yang semula menggunakan metode pembayaran tunai menjadi pembayaran nontunai (e-toll) memberikan dampak pada penggunaan sumber daya manusia yang bertugas sebagai toll collector. Sistem pembayaran tunai mengharuskan masingmasing gardu pembayaran diisi oleh satu petugas toll collector, sedangkan sistem pembayaran nontunai (e-toll) dapat merampingkan penggunaan sumber daya manusia menjadi satu petugas toll collector 
bertanggung jawab atas tiga GTO (Gardu Tol Otomatis) terkecuali gardu permbayaran saldo kurang/top-up masing-masing gardu diharuskan diisi oleh satu petugas toll collector. Kinerja sistem antrian untuk masing-masing shift I dan II yang saat ini mengoperasikan delapan fasilitas pelayanan (server) atau gardu pembayaran masih belum optimal, baik dari kinerja sistem antrian berdasarkan panjang kemacetan maupun jumlah kendaraan. Alternatif solusi jumlah yang sebaiknya dioperasikan oleh PT. Jasa Marga untuk mencapai titik optimum yaitu sebelas fasilitas pelayanan (server) atau gardu. Salah satu penyebab sering terjadinya kepadatan sehingga menimbulkan terjadinya antrian dikarenakan wawasan masyarakat yang masih kurang terkait jalannya operasional pembayaran nontunai (e-toll) yang diberlakukan untuk sistem pembayaran tol saat ini.

\section{DAFTAR PUSTAKA}

Anthara, I Made Aryantha. (2014). Analisis Sistem Antrian Gerbang Tol Pasteur Bandung di PT Jasa Marga (Persero)TBK. Majalah Ilmiah Unikom, 12(1). https://repository.unikom.ac.id/3040 7/

Berhan, E. (2015). Bank Service Performance Improvements Using Multi Sever Queue System. IOSR Journal of Business and Management, 17(6), Ver. I, 65-69. https://doi.org/10.9790/487X17616569

Heizer, J., Render, B., \& Munson, C. (2017). Principles of Operations Management, Tenth Edition. England: Pearson Education Limited.

Na, S., \& Zhiqin, S. (2015). The Analysis of ATM Queuing Phenomenon on Campus. Apllied Mechanics and Materials, 156, 1117-1121. https://doi.org/10.4028/www.scientif ic.net/AMM.155-156.1117

Pradana, M. Fakhruriza, Dwi Esti Intari \& Sketsa Gusnawan. (2018). Evaluasi Kinerja dan Pelayanan Gerbang Tol
Existing Pelabuhan Bakauheni Beserat Pengaruh Jalan Tol Trans Sumatra Terhadap Gerbang Tol Existing Bakauheni. Jurnal Fondasi, 7 (1)

Prayoga, D. D., Pondaag, J. J., \& Tumewu, F. (2017). Analysis of Queue System and Optimization of Teller Service at PT. Bank Sulutgo, Jurnal EMBA, 5(2), 928-934

Russell, R. S., \& Taylor, B. W. (2011). Operation Management. USA: John Wiley \& Son, Inc

Santoso, C. H., Tannady, H \& Caesaron, D., (2015). Analisis Kemacetan di Jalan Tol Lingkar Dalam Kota Jakarta (Gerbang Tol Cililitan). Jurnal Teknik dan Ilmu Komputer, 4 (14), 163-174.

Sya'diyah, E., \& Suryowati, K. (2017). Analisis Sistem Antrian pada Pelayanan Teller di Bank Rakyat Indonesia Kantor Cabang Kota Tegal. Jurnal Statistika Industri dan Komputasi, 2(1), 12-20.

Vass, H., \& Szabo, Z. K. (2015). Application of Queuing Model to Patient Flow in Emergency. Procedia Economics and Finance, 32(15), 479-487. https://doi.org/10.1016/S22125671(15)01421-5 